\title{
Quality of Life Impairment in Children and Adults with Vitiligo: A Cross-Sectional Study Based on Dermatology-Specific and Disease-Specific Quality of Life Instruments
}

\author{
Juliana Catucci Boza Natalia Giongo Priscilla Machado Roberta Horn \\ Amanda Fabbrin Tania Cestari \\ Department of Dermatology, Hospital de Clínicas de Porto Alegre, Federal University of Rio Grande do \\ Sul - Postgraduate Programs in Child and Adolescent Health, Porto Alegre, Brazil
}

\section{Key Words \\ Quality of life · Vitiligo · Pigmentation disorders · Lifestyle}

\begin{abstract}
Background: Vitiligo can negatively affect a patient's quality of life (QoL). A specific questionnaire has been developed and validated in the English language: the vitiligo-specific quality-of-life instrument (VitiQoL). The instrument was translated, culturally adapted and validated into Brazilian Portuguese (VitiQoL-PB). Objective: The aim of this study was to assess the QoL in adult patients through the VitiQoL and Dermatology Life Quality Index (DLQI) and in pediatric patients through the Children's Dermatology Life Quality Index (CDLQI) in a sample of patients with vitiligo. Methods: Subjects were selected from a dermatological outpatient clinic and from a private practice in Porto Alegre. The QoL of pediatric patients was evaluated using the CDLQI questionnaire. In adult patients we used the VitiQoL-PB and the DLQI. Results: A strong correlation between the scores of the total VitiQoL and DLQI was observed $(r=0.81 ; p<0.001)$. The factor that most contributed to the final score of VitiQoL was stigma. In our sample, women had higher scores than men $(p<0.05)$. Psychiatric problems were associated with lower
\end{abstract}

QoL. In the pediatric population, the median score of the CDLQI was 3 (interquartile range 1.3-7.3). There was a statistically significant correlation between the child's age and the CDLQI score $\left(r_{s}=0.41, p=0.044\right)$. Conclusion: This study confirms that the VitiQoL is easy to administer and adds important information about the impact of vitiligo on a South American population. Stigmatization is very present in the disease. There are groups of patients that are more vulnerable, like women, patients with psychiatric diseases and adolescents.

(c) 2016 S. Karger AG, Basel

\section{Background}

Vitiligo is a common skin disease which has been reported to affect approximately $1 \%$ of the population worldwide. It affects people of any age or ethnicity, more than half of whom develop it before the age of 20 years. Vitiligo is clinically characterized by the development of white macules due to the loss of functioning melanocytes in the skin, hair, or both. The cause of this condition is uncertain but seems to be dependent on the interaction of genetic, immunological and neurogenic factors $[1,2]$. 


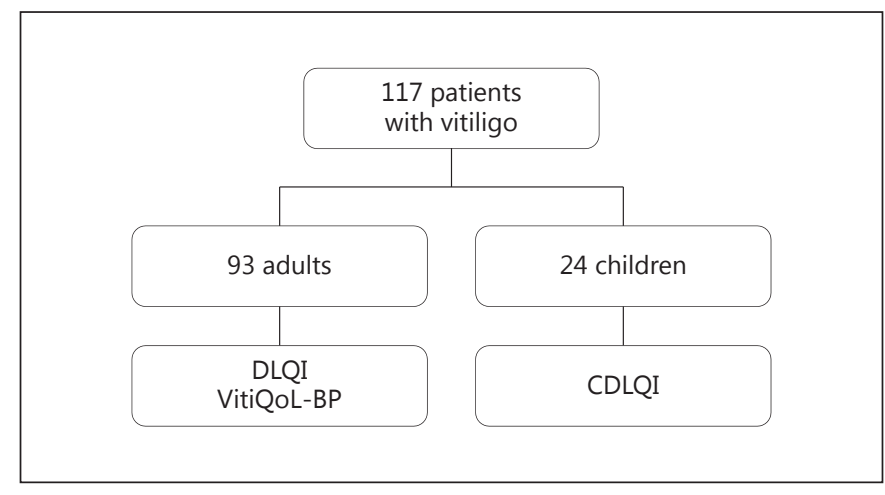

Fig. 1. Flowchart of the Methods.

Chronic skin conditions can impact a patient's quality of life (QoL) beyond the skin. Vitiligo can negatively affect a patient's QoL, the disorder can be psychologically devastating and stigmatizing. Patients with vitiligo are mostly affected by their psychosocial well-being, whereas patients with other chronic skin conditions such as psoriasis and atopic dermatitis are affected by both physical and psychosocial well-being [3-7].

A disease-specific questionnaire for vitiligo has been developed and validated in the English language: the vitiligo-specific quality-of-life instrument (VitiQoL) [4]. The VitiQoL is a questionnaire of 15 items, with item scores from 0 (never) to 6 (all the time). It yields a total score from 0 to 90 . The 16th question of the VitiQoL questionnaire is a self-reported severity scale ranging from 0 (no skin involvement) to 6 (severest case).

The questionnaire proved to be a promising clinical and epidemiological study instrument, and a powerful marker of the treatment outcome. An exploratory factor analysis with oblique rotation yielded 3 factors: participation limitation, stigma, and behavior. The instrument was translated, culturally adapted and validated into Brazilian Portuguese (VitiQoL-PB) [8].

As the disease usually begins in childhood or young adulthood, pediatric patients are also affected, and the repercussions of the disease in the pediatric population have also been studied quite extensively $[9,10]$. The most widely used questionnaire is the Children's Dermatology Life Quality Index (CDLQI), which is a questionnaire of 10 items that can be used on children and adolescents from 5 to 16 years old. The score ranges from 0 to 30 , and the higher the score, the worse the QoL.

The measurements of QoL have a lot of importance in dermatology. Skin diseases, in the vast majority of cases, do not imply a life's risk, however, strongly influence pa- tients' emotional state, social relations and daily activities. Many times, evaluating the influence of the disease differs between the patient and the doctor, which can interfere directly in the management of the disorder. The analysis of responses to questionnaires on QoL allows us to establish the relationship between the disease and the overall impact on the patient's life and, thereby, analyze more satisfactory indications and the result of certain treatments [11-13].

The Dermatology Life Quality Index (DLQI) was developed in 1994 and was the first QoL assessment tool in dermatology. It is a dermatology-specific questionnaire of 10 items, and the scores range from 0 to 30; the higher the score, the worse the QoL [14].

The relationship between QoL and treatment is also well established for other diseases, such as psoriasis [15]. There are few publications that specifically address clinical and epidemiological characteristics with QoL in different age groups. Besides that, till today in Brazil, there's no available data about the aspects of QoL using a diseasespecific questionnaire for vitiligo. Dermatology-specific instruments are useful and allow comparisons with other dermatoses; however, it is recognized that disease-specific instruments for each disease are more sensitive.

Therefore, this study was undertaken to assess clinical and sociodemographic characteristics that adversely affect the QoL in different age groups of patients with vitiligo so that these variables could be considered in their treatment and care.

\section{Objective}

The aim of this study was to assess the QoL in adult patients through VitiQoL-PB and DLQI and pediatric patients through CDLQI in a sample of patients with vitiligo in southern Brazil, and its relation with demographic data and clinical characteristics.

\section{Methods}

For further details, see the supplementary materials (for all online suppl. material, see www.karger.com/doi/10.1159/000448656) $[4,8,16]$ (fig. 1).

\section{Results}

We included a total of 117 patients, 93 adults and 24 children. Table 1 shows the clinical and demographic data of patients. 
Table 1. Clinical and demographic data

\begin{tabular}{|c|c|c|c|}
\hline & $\begin{array}{l}\text { Adults } \\
(\mathrm{n}=93)\end{array}$ & $\begin{array}{l}\text { Children } \\
(\mathrm{n}=24)\end{array}$ & $\mathrm{p}$ \\
\hline Female sex & $63(67.7)$ & $12(50.0)$ & 0.169 \\
\hline Age, years & $45.7 \pm 16.9$ & $10.04 \pm 4.102$ & $<0.001$ \\
\hline Civil state: married & $36(38.7)$ & - & 0.001 \\
\hline $\begin{array}{l}\text { Education } \\
<12 \text { years } \\
\text { High school graduate } \\
\text { Graduate, professional } \\
\text { school or postgraduate }\end{array}$ & $\begin{array}{l}32(34.4) \\
35(37.6)\end{array}$ & $\begin{array}{r}21(87.5) \\
3(12.5)\end{array}$ & $<0.001$ \\
\hline $\begin{array}{l}\text { Income/by month } \\
<\text { USD } 250 \\
\text { USD } 250-750 \\
\text { >USD } 750\end{array}$ & $\begin{array}{l}28(30.8) \\
44(48.4) \\
19(20.9) \\
\end{array}$ & $\begin{aligned} & 9(37.5) \\
& 13(54.2) \\
& 2(8.3) \\
&\end{aligned}$ & 0.362 \\
\hline Duration of vitiligo, years & $13.9 \pm 12.82$ & $3.98 \pm 3.164$ & $<0.001$ \\
\hline Age at onset, years & $31.81 \pm 20.48$ & $5.96 \pm 3.873$ & $<0.001$ \\
\hline Family history & $20(22.7)$ & $4(18.2)$ & 0.778 \\
\hline Triggering event & $65(69.9)$ & $10(41.7)$ & 0.020 \\
\hline Symptoms & $40(43.0)$ & $12(50.0)$ & 0.701 \\
\hline$\underline{\mathrm{KP}}$ & $44(47.3)$ & $9(37.5)$ & 0.492 \\
\hline \multicolumn{4}{|l|}{ Disease activity } \\
\hline \multicolumn{4}{|l|}{ Affected area } \\
\hline Head & $79(84.9)$ & $19(79.2)$ & 0.538 \\
\hline Trunk & $64(68.8)$ & $9(37.5)$ & 0.010 \\
\hline Arms & $48(51.6)$ & $12(50.0)$ & 0.999 \\
\hline Legs & $57(61.3)$ & $13(54.2)$ & 0.688 \\
\hline Hand and foot & $65(69.9)$ & $7(29.2)$ & 0.001 \\
\hline Involvement & & & 0.079 \\
\hline Unilateral & $9(9.7)$ & $6(25.0)$ & \\
\hline Bilateral & $84(90.3)$ & $18(75.0)$ & \\
\hline Classification & & & 0.999 \\
\hline Segmental & $8(8.6)$ & $2(8.3)$ & \\
\hline Nonsegmental & $85(91.4)$ & $22(91.7)$ & \\
\hline Areas not covered by clothes & $84(90.3)$ & $20(83.3)$ & 0.464 \\
\hline Phototype & & & 0.581 \\
\hline II & $26(28.0)$ & $9(37.5)$ & \\
\hline III & $35(37.6)$ & $9(37.5)$ & \\
\hline IV & $27(29.0)$ & $4(16.7)$ & \\
\hline $\mathrm{V}$ & $5(5.4)$ & $2(8.3)$ & \\
\hline
\end{tabular}

Categorical variables described by numbers with percentages in parentheses and quantitative variables as means \pm standard deviation.

The most common triggering events reported by children and adults were death of a close relative or friend and fights or disagreements. Regarding the Koebner phenomenon (KP), in 23 (24.7\%) the diagnosis was based on history and $21(22.6 \%)$ had $\mathrm{KP}$ on examination. In children, $5(20.8 \%)$ had a history of KP, and in 4 (16.7) it was observed on examination.

Quality of Life in Children and Adults with Vitiligo
Table 2. Descriptive table of scores in the adult sample

\begin{tabular}{lcccr}
\hline & Median & $\begin{array}{l}\text { Interquartile } \\
\text { range }\end{array}$ & $\begin{array}{l}\text { Mini- } \\
\text { mum }\end{array}$ & $\begin{array}{l}\text { Maxi- } \\
\text { mum }\end{array}$ \\
\hline VitiQoL total & 37.00 & $17.00-61.50$ & 0.00 & 90.00 \\
Participation limitation & 14.23 & $3.00-22.50$ & 0.00 & 42.00 \\
Stigma & 16.75 & $7.00-26.50$ & 0.00 & 30.00 \\
Behavior & 9.15 & $5.00-14.00$ & 0.00 & 18.00 \\
VitiQoL 16 & 3.6 & $2.00-5.00$ & 0.00 & 6.00 \\
DLQI & 3.00 & $1.00-6.50$ & 0.00 & 29.00 \\
\hline
\end{tabular}

Data presented as medians and interquartile ranges (25th percentile to 75th percentile).

Table 3. Scores between adult men and women

\begin{tabular}{lcll}
\hline & $\begin{array}{l}\text { Men } \\
(\mathrm{n}=30)\end{array}$ & $\begin{array}{l}\text { Women } \\
(\mathrm{n}=63)\end{array}$ & $\mathrm{p}$ \\
\hline VitiQoL total & $27.0(11.8-49.5)$ & $41.0(22.0-66.0)$ & 0.011 \\
Participation limitation & $7.0(1.8-16.0)$ & $13.0(5.0-26.0)$ & 0.029 \\
Stigma & $15.5(4.8-23.3)$ & $20.0(10.0-29.0)$ & 0.043 \\
Behavior & $6.0(2.5-10.3)$ & $11.0(6.0-16.0)$ & 0.001 \\
VitiQoL 16 & $3.0(1.0-4.3)$ & $4.0(3.0-6.0)$ & 0.023 \\
DLQI & $2.0(0-5.3)$ & $3.0(2.0-8.0)$ & 0.041 \\
\hline
\end{tabular}

Data presented as medians with interquartile ranges in parentheses.

Table 4. Scores between patients with and without psychiatric illness

\begin{tabular}{llll}
\hline & $\begin{array}{l}\text { With psychiatric } \\
\text { illness } \\
(\mathrm{n}=49)\end{array}$ & $\begin{array}{l}\text { Without psychiatric } \\
\text { illness } \\
(\mathrm{n}=44)\end{array}$ & $\mathrm{p}$ \\
\hline $\begin{array}{l}\text { VitiQoL total } \\
\text { Participation }\end{array}$ & $47.0(23.5-76.0)$ & $28.5(14.25-50.5)$ & 0.011 \\
$\quad$ limitation & $13.0(4.5-33.5)$ & $7.5(2.0-17.8)$ & 0.009 \\
Stigma & $22.0(10.0-29.5)$ & $14.0(6.3-24.0)$ & 0.016 \\
Behavior & $11.0(5.0-16.5)$ & $6.5(4.3-12.0)$ & 0.061 \\
VitiQoL 16 & $4.0(3.0-6.0)$ & $3.0(2.0-5.0)$ & 0.011 \\
DLQI & $3.0(1.5-8.5)$ & $2.5(1.0-5.0)$ & 0.151 \\
\hline
\end{tabular}

Data presented as medians with interquartile ranges in parentheses.

Table 2 describes the scores of QoL questionnaires in adults. The factor that had higher scores was stigma (median $=18$ ). A correlation was observed between total VitiQoL score and participation limitation $\left(\mathrm{r}_{\mathrm{s}}=0.94 ; \mathrm{p}<\right.$ $0.001)$, stigma $\left(r_{s}=0.94 ; \mathrm{p}<0.001\right)$ and behavior $(r=0.80$; $\mathrm{p}<0.001$ ).

A strong correlation between the scores of the total VitiQoL and DLQI was observed $(r=0.81 ; p<0.001)$, as 
Table 5. Impact of vitiligo on individual aspects of lifestyle and QoL in adults, children and adolescents: correlation of DLQI and CDLQI headings with the total score of each instrument

\begin{tabular}{|c|c|c|c|c|c|}
\hline DLQI headings & Questions & $\begin{array}{l}\text { Adults } \\
\mathrm{r}_{\mathrm{s}}\end{array}$ & CDLQI headings & Questions & $\begin{array}{l}\text { Children } \\
r_{s}\end{array}$ \\
\hline $\begin{array}{l}\text { Symptoms and } \\
\text { feelings }\end{array}$ & $\begin{array}{l}\text { Q1 Scratchy/sore/ } \\
\text { painful skin } \\
\text { Q2 Self-conscious about } \\
\text { lesions }\end{array}$ & $0.76(<0.001)$ & $\begin{array}{l}\text { Symptoms and } \\
\text { feelings }\end{array}$ & $\begin{array}{l}\text { Q1 Scratchy/sore/ } \\
\text { painful skin } \\
\text { Q2 Self-conscious } \\
\text { about lesions }\end{array}$ & $0.68(<0.001)$ \\
\hline Leisure & $\begin{array}{l}\text { Q5 Social/leisure } \\
\text { activities } \\
\text { Q6 Sports }\end{array}$ & $0.84(<0.001)$ & Leisure & $\begin{array}{l}\text { Q4 Clothing } \\
\text { decisions } \\
\text { Q5 Going out/ } \\
\text { playing hobbies } \\
\text { Q6 Sports }\end{array}$ & $0.74(<0.001)$ \\
\hline Work and school & Q7 Schoolwork & $0.39(<0.001)$ & School or holidays & Q7 Schoolwork & $0.43(0.036)$ \\
\hline Personal relationships & $\begin{array}{l}\text { Q8 Partner/close } \\
\text { friends/relatives } \\
\text { Q9 Sexual }\end{array}$ & $0.66(<0.001)$ & Personal relationships & $\begin{array}{l}\text { Q3 Friendships } \\
\text { Q8 Teasing and } \\
\text { bullying }\end{array}$ & $0.73(<0.001)$ \\
\hline Treatment & Q10 Treatment & $0.36(<0.001)$ & Treatment & Q10 Treatment & $0.16(0.469)$ \\
\hline
\end{tabular}

$\mathrm{r}_{\mathrm{s}}=$ Spearman correlation coefficient; $\mathrm{p}$ values indicated in parentheses.

well as their specific areas of participation limitation $\left(\mathrm{r}_{\mathrm{s}}=\right.$ $0.70 ; \mathrm{p}<0.001)$, stigma $\left(\mathrm{r}_{\mathrm{s}}=0.80 ; \mathrm{p}<0.001\right)$ and behavior $\left(r_{s}=0.66 ; p<0.001\right)$. A correlation was also observed between the total VitiQoL and the self-reported severity of the VitiQoL item $16\left(r_{s}=0.70 ; p<0.001\right)$.

In our sample, women had higher scores than men, with a statistically significant difference, as can be seen in table 3.

Regarding the previous diagnosis of psychiatric illness, higher scores of the total VitiQoL were observed in patients with psychiatric illness, as it can be seen in table 4 . There was no statistical difference in DLQI and in the question 16 of the VitiQoL regarding psychiatric illness.

When performing multiple linear regression, the relationship between women and psychiatric disease remained as significant independent predictors of VitiQoL $(\mathrm{p}<0.05)$. VitiQoL item 16 was also correlated with the percentage of the total affected area of the body ( $\mathrm{p}=$ 0.016). There was no correlation between QoL scores in adults and some variables such as age, marital status, education, income, vitiligo classification, areas covered by clothes, phototype and disease activity.

In the pediatric population, the average CDLQI for children was 3, with an interquartile range of 1.3-7.3. There was a statistically significant correlation between the child's age and the score on the CDLQI $\left(\mathrm{r}_{\mathrm{s}}=0.41 ; \mathrm{p}=\right.$ 0.044). The median CDLQI score found in the present study was significantly higher in adolescents aged 15 years and older (median $=11$, interquartile range $=4.75$ $14.25, \mathrm{p}=0.04)$. There was no difference between boys and girls $(p=0.219)$, and no relationship between CDLQI and the affected area of the body or the extent of the disease either $(p>0.005)$. The impact of vitiligo on different aspects of QoL in children and adolescents is presented in table 5. Table 5 describes the correlation of DLQI and CDLQI headings with the total score of each instrument.

The questions with highest average scores among adults and children were questions 2 and 4 . Question 2 is about self-consciousness about lesions and question 4 about decision of which clothes to wear in both instruments.

\section{Discussion}

The VitiQoL score in our sample was similar to that found in the original study [4]. Our study did not find any difference in the scores between the areas covered and not covered either, even taking into consideration that the majority of the patients in our sample (over 90\%) showed 
lesions in visible areas. Although some studies have found an association between lower QoL and involvement of visible areas such as the face, neck and hands $[17,18]$, others did not observe such findings [19].

The most important factor that contributed to the total score of VitiQoL was stigma. We had already found a similar result when we validated the VitiQoL to Brazilian Portuguese [8], because, in both studies, as well as in the original VitiQoL study [4], the single item that most contributed to the total score was related to the frustration about the skin condition (question 2). This aspect is quite important, since it has already been observed that selfesteem of patients is greatly affected and that stigmatization is very present in the disease, as already assessed in previous studies [20,21].

Several studies indicated a greater impairment of QoL in women [22, 23]. It is interesting to consider also that, despite the fact that vitiligo affects both sexes, women seek medical care more often than men due to a great concern about skin appearance and the related psychosocial effects [24]. Regarding vitiligo-specific questionnaires, the Vitiligo Impact Scale-22 [25] also showed higher scores in females. Nevertheless, there are also studies that did not observe any differences between the sexes regarding the QoL in vitiligo [26].

As in previous studies with VitiQoL, there was a correlation between the VitiQoL and the DLQI and the individual patient's assessment of the severity of the disease $[4,8]$. Similarly, other specific questionnaires for vitiligo had shown a correlation with the DLQI $[25,27,28]$.

A very important aspect of vitiligo is the high prevalence of psychiatric disorders in these patients. It has been observed that the presence of psychiatric illness is related to a higher incidence of QoL impairment [29]. In our study it was also shown that patients who spontaneously reported a previous psychiatric diagnosis also had higher VitiQoL scores. A similar relation was demonstrated in other dermatological diseases when evaluated by a disease-specific questionnaire, as in melasma [30].

Vitiligo affects significantly also multiple aspects of the QoL of children and adolescents [31]. The average CDLQI was 3, similar to the data from other studies, both international [32], as well as those that were carried out in Brazil [33]. There was a statistically significant correlation between the child's age and the score on the CDLQI. This aspect is present in other studies, and the reason for this association may be the fact that the QoL impairment usually occurs when children develop a sense of competence and socialization in school as well as self-identity [32]. A limitation to our study is the relatively small sample size

Quality of Life in Children and Adults with Vitiligo of children and adolescents, and the calculated sample size for adults was 99 but we included 93 adult patients.

Besides the QoL, some clinical features are present in adults and children, and should be taken into consideration in the management of the disease. A triggering factor is very common in the history of patients, once they correlate the appearance of the lesions with some notable event of their lives [34]. Another interesting aspect is that, despite the vitiligo being considered asymptomatic, $43 \%$ of adult patients and $50 \%$ of pediatric ones reported associated symptoms. Previous studies demonstrated that itching and burning skin occurs in one third of patients [9]. Discussed potential mechanisms for such skin symptoms include higher-grade inflammation, higher sensitivity to sunburns and also possibly the adverse effects of some treatments, like phototherapy and the use of calcineurin inhibitors.

The $\mathrm{KP}$ is very common in vitiligo patients. Type $1 \mathrm{KP}$ is defined as the diagnosis of KP made on the basis of history. Type $2 \mathrm{~A} \mathrm{KP}$ is based on evidence of trauma-induced depigmentation on physical examination and type $2 \mathrm{~B} \mathrm{KP}$ by linear streaks of depigmentation on examination. A recent study reported that KP was seen in 130 of 202 patients (64.4\%) [35]. In this study the majority of diagnoses was based on physical examination (type $2 \mathrm{~A}$ ), but in our study, many patients were also diagnosed by previous history taking (type 1).

Although the DLQI and CDLQI are not directly comparable, most of the questions are the same, as well as the headings. The main heading item in adults influenced by disease was leisure, followed by symptoms and feelings and daily activities $(\mathrm{p}<0.001)$, which is in agreement with Ongenae et al. [36] and Wang et al. [12]. In children, the main heading item influenced by disease was also leisure, and vitiligo had a highly significant impact on personal relationships; the item includes questions about friendships, teasing and bullying.

Vitiligo seems to have less influence on activities such as going to work and school, and this is in agreement with the results of other studies [12, 18, 22]. Leisure, social activities and sports seem to have a higher impact on QoL, and it may be related to self-consciousness about lesions and clothing decisions, since those were the questions that had higher scores in the DLQI and also in the CDLQI. Unlike other studies [37], treatment does not seem to have such an impact on QoL, in both adults and children, in our sample.

When comparing the dermatology-specific with the disease-specific questionnaire, it is observed that there are more questions in VitiQoL related to stigmatization 
of the disease, which is a very important aspect of vitiligo. Feelings such as frustration, embarrassment/self-consciousness and concern about the reaction of what other people may think about the patient are better explored in the VitiQoL. As in dermatology-specific questionnaires (DLQI and CDLQI), daily activities seem to be less affected than leisure and social activities. And the decision of the clothes to wear is also a concern in the disease-specific instrument.

The use of disease-specific instruments to assess QoL helps in the management of patients. The present study showed how much stigma is present in the lives of patients with vitiligo. Besides that assessment of QoL provides relevant information about treatment benefits, the importance of early treatment and understanding of the profound psychosocial effect of vitiligo correlate with positive QoL outcomes and prevent social and emotion- al limitations that can result from the disease $[7,10]$. Patients may benefit from referrals for psychological intervention and early treatment [9]. Finally, this study contributes to gather evidence on the Brazilian Portuguese version of the VitiQoL, encouraging other groups to develop more studies about QoL in larger populations.

\section{Statement of Ethics} tution.

The study was approved by the ethical committee of our insti-

\section{Disclosure Statement}

The authors have no conflicts of interest to declare.

\section{References}

1 Ezzedine K, Eleftheriadou V, Whitton M, van Geel N: Vitiligo. Lancet 2015;386:74-84.

2 Van Geel N, Speeckaert M, Brochez L, Lambert J, Speeckaert R: Clinical profile of generalized vitiligo patients with associated autoimmune/autoinflammatory diseases. J Eur Acad Dermatol Venereol 2014;28:741-746.

3 Ramien ML, Ondrejchak S, Gendron R, Hatami A, McCuaig CC, Powell J, Marcoux D: Quality of life in pediatric patients before and after cosmetic camouflage of visible skin conditions. J Am Acad Dermatol 2014;71:935940.

4 Lilly E, Lu PD, Borovicka JH, Victorson D, Kwasny MJ, West DP, Kundu RV: Development and validation of a vitiligo-specific quality-of-life instrument (VitiQoL). J Am Acad Dermatol 2013;69:e11-e18.

5 Choi S, Kim DY, Whang SH, Lee JH, Hann SK, Shin YJ: Quality of life and psychological adaptation of Korean adolescents with vitiligo. J Eur Acad Dermatol Venereol 2010;24: 524-529.

6 Al-Shobaili HA: Treatment of vitiligo patients by excimer laser improves patients' quality of life. J Cutan Med Surg 2014;18:1-7.

7 Eleftheriadou V, Thomas KS, Whitton ME, Batchelor JM, Ravenscroft JC: Which outcomes should we measure in vitiligo? Results of a systematic review and a survey among patients and clinicians on outcomes in vitiligo trials. Br J Dermatol 2012;167:804-814

8 Boza JC, Kundu RV, Fabbrin A, Horn R, Giongo N, Cestari TF: Translation, cross-cultural adaptation and validation of the vitiligospecific health-related quality of life instrument (VitiQoL) into Brazilian Portuguese. An Bras Dermatol 2015;90:358-362.
9 Silverberg JI, Silverberg NB: Quality of life impairment in children and adolescents with vitiligo. Pediatr Dermatol 2014;3:309-318.

10 Weber MB, Lorenzini D, Reinehr CP, Lovato $\mathrm{B}$ : Assessment of the quality of life of pediatric patients at a center of excellence in dermatology in southern Brazil. An Bras Dermatol 2012;87:697-702.

11 Felsten LM, Alikhan A, Petronic-Rosic V: Vitiligo: a comprehensive overview. II. Treatment options and approach to treatment. J Am Acad Dermatol 2011;65:493-514.

12 Wang KY, Wang KH, Zhang ZP: Health-related quality of life and marital quality of vitiligo patients in China. J Eur Acad Dermatol Venereol 2011;25:429-435.

13 Linthorst Homan MW, Spuls PI, de Korte J, Bos JD, Sprangers MA, van der Veen JP: The burden of vitiligo: patient characteristics associated with quality of life. J Am Acad Dermatol 2009;61:411-420.

14 Finlay AY, Khan GK: Dermatology Life Quality Index (DLQI) - a simple practical measure for routine clinical use. Clin Exp Dermatol 1994;19:210-216

15 Simpson MJ, Chow C, Morgenstern H, Luger TA, Ellis CN: Comparison of three methods for measuring psoriasis severity in clinical studies (part 2 of 2): use of quality of life to assess construct validity of the Lattice System Physician's Global Assessment, Psoriasis Area and Severity Index and Static Physician's Global Assessment. J Eur Acad Dermatol Venereol 2015;29:1415-1420.
16 Taieb A, Picardo M: The definition and assessment of vitiligo: a consensus report of the Vitiligo European Task Force. Pigment Cell Res 2007;20:27-35.

17 Wong S, Bao MBBCH, Baba R: Quality of life among Malaysian patients with vitiligo. Int J Dermatol 2012;51:156-161.

18 Ingordo V, Cazzaniga S, Medri M, Raone B, Digiuseppe MD, Musumeci ML, Romano I, Fai D, Pellegrino M, Pezzarossa E, Di Lernia V, Peccerillo F, Battarra VC, Sirna R, Patrizi A, Naldi L: To what extent is quality of life impaired in vitiligo? A multicenter study on Italian patients using the dermatology life quality index. Dermatology 2014;229:240247.

19 Mashayekhi V, Javidi Z, Kiafar B, Manteghi AA, Saadatian V, Esmaeili HA, Hosseinalizadeh S: Quality of life in patients with vitiligo: a descriptive study on 83 patients attending a PUVA therapy unit in Imam Reza Hospital, Mashad. Indian J Dermatol Venereol Leprol 2010;76:592.

20 Kent G, al-Abadie M: Factors affecting responses on Dermatology Life Quality Index items among vitiligo sufferers. Clin Exp Dermatol 1996;21:330-333.

21 Ongenae K, Dierckxsens L, Brochez L, van Geel N, Naeyaert JM: Quality of life and stigmatization profile in a cohort of vitiligo patients and effect of the use of camouflage. Dermatology 2005;210:279-285.

22 Karelson M, Silm H, Kingo K: Quality of life and emotional state in vitiligo in an Estonian sample: comparison with psoriasis and healthy controls. Acta Derm Venereol 2013; 93:446-450. 
23 Ingordo V, Cazzaniga S, Medri M, Raone B, Digiuseppe MD, Musumeci ML, Romano I, Fai D, Pellegrino M, Pezzarossa E, Di Lernia V, Peccerillo F, Battarra VC, Sirna R, Patrizi A, Naldi L: To what extent is quality of life impaired in vitiligo? A multicenter study on Italian patients using the Dermatology Life Quality Index. Dermatology 2014;229:240247.

24 Alikhan A, Felsten LM, Daly M, PetronicRosic V: Vitiligo: a comprehensive overview. I. Introduction, epidemiology, quality of life, diagnosis, differential diagnosis, associations, histopathology, etiology, and work-up. J Am Acad Dermatol 2011;65:473-491.

25 Gupta V, Sreenivas V, Mehta M, Khaitan BK, Ramam M: Measurement properties of the Vitiligo Impact Scale-22 (VIS-22), a vitiligospecific quality-of-life instrument. Br J Dermatol 2014;171:1084-1090.

26 Al Robaee AA: Assessment of quality of life in Saudi patients with vitiligo in a medical school in Qassim province, Saudi Arabia. Saudi Med J 2007;28:1414-1417.
27 Şenol A, Yücelten AD, Ay P: Development of a quality of life scale for vitiligo. Dermatology 2013;226:185-190.

28 Ezzedine K, Grimes PE, Meurant JM, Seneschal J, Léauté-Labrèze $C$, Ballanger $F$, Jouary T, Taïeb C, Taïeb A: Living with vitiligo: results from a national survey indicate differences between skin phototypes. Br J Dermatol 2015;173:607-609.

29 Sangma LN, Nath J, Bhagabati D: Quality of life and psychological morbidity in vitiligo patients: a study in a teaching hospital from north-East India. Indian J Dermatol 2015;60: 142-146.

30 Freitag FM, Cestari TF, Leopoldo LR, Paludo P, Boza JC: Effect of melasma on quality of life in a sample of women living in southern Brazil. J Eur Acad Dermatol Venereol 2008;22: 655-662.

31 Krüger C, Panske A, Schallreuter KU: Disease-related behavioral patterns and experiences affect quality of life in children and adolescents with vitiligo. Int J Dermatol 2014;53: 43-50.

32 Silverberg JI, Silverberg NB: Quality of life impairment in children and adolescents with vitiligo. Pediatr Dermatol 2014;31:309-318.
33 Manzoni APD da S, Pereira RL, Townsend RZ, Weber MB, Nagatomi AR da S, Cestari TF: Assessment of the quality of life of pediatric patients with the major chronic childhood skin diseases. An Bras Dermatol 2012;87:361368.

34 Behl PN, Kotia A, Sawal P: Vitiligo: age-group related trigger factors and morphological variants. Indian J Dermatol Venereol Leprol 1994;60:275-279.

35 Kanwar AJ, Mahajan R, Parsad D: Type 2A Koebner phenomenon in vitiligo is distinct from other subtypes: observations from an Indian cohort. Br J Dermatol 2014;170:586590.

36 Ongenae K, Van Geel N, De Schepper S, Naeyaert JM: Effect of vitiligo on self-reported health-related quality of life. Br J Dermatol 2005; 152:1165-1172.

37 Sangma LN, Nath J, Bhagabati D: Quality of life and psychological morbidity in vitiligo patients: a study in a teaching hospital from north-East India. Indian J Dermatol 2015;60: 142-146. 